\title{
STEREOLOGICAL ESTIMATION OF ITO CELLS FROM RAT LIVER USING THE OPTICAL FRACTIONATOR - A PRELIMINARY REPORT
}

\author{
RICARDO MARCOS $^{1}$, EDUARDO ROCHA ${ }^{1,2}$ AND ROGÉRIO AF MONTEIRO ${ }^{1,2}$ \\ ${ }^{1}$ Lab. Histology and Embryology, Institute of Biomedical Sciences Abel Salazar (ICBAS), Lg. Prof. Abel \\ Salazar no. 2, 4099-003 Porto, ${ }^{2}$ Multidisciplinary Center for Marine and Environmental Research (CIIMAR), \\ Portugal \\ e-mail: histo@icbas.up.pt \\ (Accepted Jannuary 28, 2002)
}

\begin{abstract}
In the last two decades, much light has been shed on hepatic fibrosis, and the activation / proliferation of Ito cells (IC) emerged to play a central role. Therefore, it is essential to have solid quantitative data in nonpathological statuses; yet, this data is scarce and confined to "number per area" or semiquantitative information. Moreover, the supposed heterogeneous distribution of IC in the hepatic lobule was never analysed with design-based (unbiased) stereology. In the present study, the total number (N) of IC in rat liver was estimated for the first time, by combining immunocytochemistry with the optical fractionator. Quantification was extended to the hepatocytes, to disclose the IC index, an often-used ratio in hepatology. Systematic uniform random liver sections were obtained from male Wistar rats $(n=3)$, and immunostained against glial fibrillary acidic protein (GFAP), a known specific marker for hepatic IC. For the first time, these were marked against GFAP in thick $(30 \mu \mathrm{m})$ paraffin sections. The estimated $\mathrm{N}$ of IC was $224 \mathrm{E}^{06}$; with a coefficient of error of 0.04 or 0.06 , depending on the particular equation used (based on the so-called "quadratic approximation"). The IC index was 91 IC/1000 hepatocytes. Concerning the lobular heterogeneity, it was proved the liver harbours a larger total number of periportal IC and hepatocytes.
\end{abstract}

Keywords: disector, hepatocytes, Ito cells, liver, optical fractionator.

\section{INTRODUCTION}

Ito cells (IC) are perisinusoidal liver cells, located in the space of Disse and between the hepatocytes. These cells, also termed interstitial cells, hepatic stellate cells, fat-storing cells or lipocytes exert four major functions: (1) storage and release of retinoids; (2) production and turnover of extracellular matrix; (3) regulation of blood-flow in the sinusoids; (4) production of mediators (Kawada, 1997). IC are normally in a quiescent, nonproliferative state, but these cells multiply when activated. This happens after partial hepatectomy, focal hepatic lesions, and in different conditions that lead to fibrosis (Geerts et al., 1994). In the last two decades, much light has been put into hepatic fibrosis, and IC clearly emerge as the principal fibrogenic cell in the liver (Kawada, 1997). To better evaluate both the activation and proliferation of IC, it is essential to have solid quantitative data in nonpathological conditions. In this vein, quantitative data has been gathered both in human and rat livers. However, this data is scarce in literature and confined to either "number per area" or to semiquantitative information. Moreover, the heterogeneous distribution of IC within the liver (Jungermann and Kietzmann, 1996) was never study with "design-based" stereology.

It is now recognised that the best strategy for estimating total cell numbers in microscopy is the optical fractionator (West et al., 1991). This technique combines the optical disector (Gundersen, 1986), a $3 \mathrm{D}$ probe that samples cells in proportion to their number, with the fractionator, in which a known fraction of the organ is sampled (systematically random). The optical fractionator does not rely on shape, size, or orientation assumptions, and is unaffected by shrinkage, thus making it ideal to use in material embedded in paraffin. However, the thick sections required by the optical disector rise problems for immunocytochemistry, often used to accurately identify the cells to be counted.

The aim of the present study was to estimate the total number (N) of GFAP-positive IC. To disclose the IC index (an often used ratio in hepatology), quantification was extended to the nucleus of hepatocytes (HEP). 


\section{MATERIALS AND METHODS}

We used four-month old male Wistar rats $(n=3)$. The animals were deeply anaesthetised with chloral hydrate and cardiacally perfused for $15 \mathrm{~min}$, using a peristaltic pump (Gilson). The fixative used was 10\% buffered formaline. Then, the liver was removed, weighted, and sliced in $4 \mathrm{~mm}$ thick slices (firstly cut at a random distance from the edge). After performing the so-called smooth fractionator (Nyengaard, 1999), a mean of 10 liver fragments was obtained per animal. These were further immersed in the same fixative used for perfusion, for 16 hours, and routinely processed for paraffin embedding. Half of the fragments were sampled, and exhaustively sectioned ( $30 \mu \mathrm{m}$ thick), according to fractionator rules (Gundersen, 1986). Every $20^{\text {th }}$ section was then systematically sampled, and, to assure reliable adhesion, mounted on precleaned slides primed with 3-aminopropiltriethoxysilane (Marcos et al., 2001).

IC marking was achieved by immunocytochemistry against glial fibrillary acidic protein (GFAP). After deparaffinization, microwave treatment was carried out for antigen retrieval (600 W, 4 plus $4 \mathrm{~min})$. After rinsing in phosphate-buffered saline (PBS), the endogenous peroxidase was blocked using $0.3 \%$ $\mathrm{H}_{2} \mathrm{O}_{2}$, for $30 \mathrm{~min}$. A streptavidin-biotin protocol then followed (Histostain Plus, Zymed). Briefly, after rinsing in PBS, a $10 \%$ nonimmune goat serum was applied over the thick sections for $90 \mathrm{~min}$, followed by an incubation with 1:3000 rabbit polyclonal antibody against GFAP (Dako), for 4 days at $4^{\circ} \mathrm{C}$. After further rinsing in PBS, the secondary antibody and the streptavidin-peroxidase complex were applied, each for $60 \mathrm{~min}$. At last, after rinsed in PBS and trisbuffered saline (TBS), sections were immersed in $0.05 \%$ 3,3'-diaminobenzidine (Sigma) in TBS and $0.03 \% \mathrm{H}_{2} \mathrm{O}_{2}$, for $10 \mathrm{~min}$. After tap water rinse, sections were counterstained in Gill's hematoxilyn, and mounted in DPX.

The following controls were performed: (1) positive control, in which astrocytes were tagged by GFAP in the rat brain; (2) negative controls, in which the first antibody was either omitted or replaced by rabbit nonimmune serum (Dako).

The $\mathrm{N}$ of IC and of HEP were estimated with the optical fractionator, using a workstation made of a microscope (Olympus, BX-50), a microcator (Heidenhain MT-12) to control the movements in $z$ axis (accuracy $0.5 \mu \mathrm{m}$ ), a motorised stage (Prior) for stepwise displacement in the $x-y$ axis (accuracy $1 \mu \mathrm{m}$ ), and a CCD video camera (Sony) connected to a 17"
PC monitor (Sony). The S-video signal was captured by the PC add-on board Screen Machine II (Fast). The VGA board (S3 Trio) was set to $800 \times 600 \mathrm{dpi}$. The whole system was controlled by the software Olympus CAST-Grid (version 1.5). A $\times 100$ oilimmersion lens (Olympus Uplan, $\mathrm{NA}=1.35$ ), providing a magnification at the monitor of $\times 4750$, allowed an accurate identification of IC. Analysis was made on live images, without further digital treatment. The first field of vision was selected randomly, and thereafter fields were sampled systematically by stepwise movements of the stage in $x$ - and $y$ directions $\left(\operatorname{step}_{\mathrm{x}, \mathrm{y}}=1250 \mu \mathrm{m}\right)$. The disector height was $20 \mu \mathrm{m}$. The software generated counting frames with defined areas $\left(1673 \mu \mathrm{m}^{2}\right.$ for IC and $418 \mu \mathrm{m}^{2}$ for HEP) and having forbidden lines to avoid edge effects (Gundersen, 1977).

A GFAP-positive IC, or a hepatocyte nucleus, were counted when two conditions were met: (1) the rim of nucleus was in focus at a plane below $4 \mu \mathrm{m}$ and above or equal to $24 \mu \mathrm{m}$ in the $z$-axis (the upper and lower surfaces were avoided with guard heights of 4 and $7 \mu \mathrm{m}$, respectively); (2) at the plane of focus, the nucleus was within the counting frame or touching the inclusion lines and did not touch the forbidden lines or their extensions. It was always evaluated whether the immunomarking extended beyond $24 \mu \mathrm{m}$, to assure that every IC could be unambiguously recognised. At the same time, in every fifth field, section thickness was measured using the microcator. After counting, the periportal (close to a portal triad) vs. pericentral (close to a central vein) location of each sampled field was inspected, with a $\times 20$ objective. When none of the landmarks were observed in the field, this was unclassified. The same author (RM) performed both the counting and the field location.

The $\mathrm{N}$ of IC, and of HEP, in the whole liver was estimated as:

$$
\mathrm{N}=\Sigma \mathrm{Q}^{-} \cdot(1 / s s f) \cdot(1 / a s f) \cdot(1 / t s f)
$$

where $\Sigma \mathrm{Q}^{-}$is the number of IC or HEP counted, $s s f$ is the fraction of sections sampled (in this case $s s f=$ $1 / 160$ ), asf is the sectional area sampled (asf $=1 / 935$ for IC, and 1/3730 for HEP), and $h s f$ is the fraction of the section thickness sampled $(h s f=0.65)$. The number of IC and HEP per gram of liver $(\mathrm{N} / \mathrm{g})$ was also calculated.

The IC index was also calculated for each rat, by the ratio:

$$
\text { IC index }=\mathrm{N}(\mathrm{IC}) .1000 / \mathrm{N}(\text { HEP })
$$


The coefficient of error (CE) of $\mathrm{N}$ was estimated applying two variants of the "quadratic approximation formula" (West et al., 1996; Gundersen et al., 1999). The CE estimations were compared with the observed total variance $\left(\mathrm{OCV}^{2}\right)$, according to the formula (West, 1993):

$$
\mathrm{OCV}^{2}=\mathrm{BCV}^{2}+\overline{\mathrm{CE}^{2}}
$$

where $\mathrm{BCV}^{2}$ is the biological variance and $\mathrm{CE}^{2}$ is the quadratic mean of the $\mathrm{CE}$ for each rat.

\section{RESULTS}

All the examined livers showed a normal histology. A consistent and reliable marking of IC was achieved with GFAP (not stained in negative controls). The IC were clearly visualised at every depth in all the sections (Fig. 1), and were distributed throughout the hepatic lobule. Most IC had clear cytoplasmic spots intermingled the GFAP staining ("reticular" pattern).

A mean of 905 disectors per rat was analysed, in which a mean of 633 IC and of 1728 HEP were counted. As to the lobular zones, 231 disectors per rat were rated pericentrally, and 166 IC and 429 HEP were counted. In periportal zones, 318 disectors were examined, thus counting 207 IC and 613 HEP. The global IC index was $91 \mathrm{IC} / 1000 \mathrm{HEP}(\mathrm{CV}=0.14)$; no significant differences were found among different zones. The N of IC and HEP are presented in Table 1, which also includes the $\mathrm{N} / \mathrm{g}$ (as it facilitates comparing animals with different liver weights), and the estimates of the CE. The mean section thickness was $31.1 \mu \mathrm{m}(\mathrm{CV}=0.01)$.

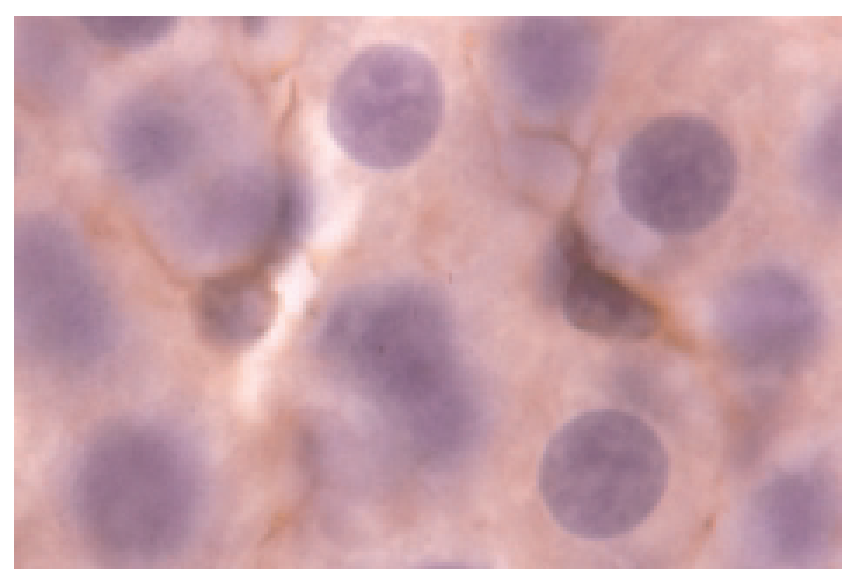

Fig. 1. Image from a $30 \mu \mathrm{m}$ thick section. Two GFAP-marked Ito cells (IC) stand out among hepatocytes and their roundish nuclei. IC display their stellate morphology. The clear vertical slit is a sinusoid. $\times 1,250$.

For estimating the $\mathrm{N}$ of IC and of HEP, and according to equation (3), the sampling procedure was responsible for $46 \%$ and $4 \%$ of total variance, respectively (i.e., the biological variance was more important in both cases). For the IC, in pericentral and periportal zones, the sampling procedure was responsible for $100 \%$ and $84 \%$ of total variance, respectively. For the HEP, in the same zones, sampling contributed to $5 \%$ and $17 \%$ of the respective total variance.

Table 1. Estimations of Ito cell (IC) and hepatocyte nucleus (HEP) number per gram of liver (N/g) and of total number $(N)$, in the whole liver, and in the pericentral and periportal zones. $C E$ is the coefficient of error of $N$, estimated according to the formula used by West et al. (1996), $C E_{1}$, and to its revised version by Gundersen et al. (1999), CE $E_{2}$. Data are expressed as Mean (Coefficient of Variation).

\begin{tabular}{lrlrlll}
\hline Parameters & \multicolumn{2}{c}{$\mathrm{N} / \mathrm{g}$} & \multicolumn{2}{c}{$\mathrm{N}$} & $\mathrm{CE}_{1}$ & $\mathrm{CE}_{2}$ \\
\hline IC & & & & & & \\
Whole liver** & $15 \mathrm{E}^{06}$ & $(0.03)$ & $224 \mathrm{E}^{06}$ & $(0,09)$ & 0.06 & 0.04 \\
Pericentral & $4 \mathrm{E}^{06}$ & $(0.03)$ & $59 \mathrm{E}^{06}$ & $(0.06)$ & 0.09 & 0.08 \\
Periportal & $5 \mathrm{E}^{06}$ & $(0.07)^{*}$ & $72 \mathrm{E}^{06}$ & $(0.09)^{*}$ & 0.09 & 0.07 \\
HEP & & & & & & \\
Whole liver** & $169 \mathrm{E}^{06}$ & $(0.13)$ & $2511 \mathrm{E}^{06}$ & $(0,24)$ & 0.05 & 0.03 \\
Pericentral & $41 \mathrm{E}^{06}$ & $(0.16)$ & $617 \mathrm{E}^{06}$ & $(0.27)$ & 0.06 & 0.05 \\
Periportal & $59 \mathrm{E}^{06}$ & $(0.06)^{*}$ & $878 \mathrm{E}^{06}$ & $(0.16)^{*}$ & 0.07 & 0.06 \\
\hline
\end{tabular}

\footnotetext{
* Indicate significant differences between pericentral and periportal zones (t-test, $\mathrm{p}<0.05$ ).

** Includes besides the pericentral and periportal, other unclassifiable zones.
} 


\section{DISCUSSION}

Ito cells ("Sternzellen") were described over a century ago, but this is the first time that an unbiased stereological tool, combined with immunocytochemistry, is applied to these cells. The immunocytochemical approach here used was mandatory, as IC cannot be distinguished in routine sections (Hall and Rojko, 1996). We tagged IC with GFAP, an intermediate filament (IF) protein recognised as a specific marker for these hepatic cells (Neubauer et al., 1996). GFAP allows a more precise identification/ quantification comparing to desmine (Niki et al., 1996), other IF protein often used to tag IC. GFAP is also preferable to other markers used so far, like vitamin A or lipid staining, as these are influenced by nutritional status and diet (Buniatian et al., 1996), and by the fact that some IC have no lipid droplets, the so-called empty IC (Sztark et al., 1986). (We also observed these empty cells, as in some of the IC the cytoplasmic "reticular" pattern - due to the usual washout of the lipid droplets - was absent.) As far as we know, this is also the first time that IC are tagged with GFAP in thick paraffin sections. The thick sections $(20-60 \mu \mathrm{m})$ required by the optical disector rise problems in immunocytochemistry to achieve marking throughout the section thickness. In our study, this was attained via long incubation times with antibodies. Other strategies, like Triton X-100 used in immunomarking rat astrocytes with GFAP (Pilegaard and Ladefoged, 1995) proved to be ineffective, according to our preliminary tests.

Quantitative studies of IC have been published (Bronfenmajer et al., 1966; Sztark et al., 1986; Geerts et al., 1991; Niki et al., 1996; Azaïs Braesco et al., 1997), using 3-10 $\mu \mathrm{m}$ sections and obtaining "numbers per area". In the stereology field, it has been often stressed that counting profile number per unit area of a section will not give a meaningful estimate of number. Number estimation of particles in a $2 \mathrm{D}$ basis is inevitability affected by the size, form, orientation, and by lost caps (Gundersen, 1986). It has been emphasised that the number of particles, being a zero-dimensional quantity, can only be estimated by a 3D probe, like the disector. The association of the optical disector with the fractionator (i.e., the optical fractionator) here used, proved as efficient as advantageous. The natural 3D alignment of the optical sections made the counting much more straightway than when using the physical disector (Marcos and Rocha, 2001). Moreover, recognition of the irregular IC profiles was facilitated, and counting the densely packed hepatocyte nuclei was made easy. The potential bias from lost caps was avoided by having upper and lower guarding zones within our thick sections, despite their use is still a matter of debate (Hatton and Von Bartheld, 1999).

Although introduced decades ago, the IC index was here estimated for the first time using a stereological approach. Our data (91 IC/1000 HEP) was inferior to previous reports, using 2D biased approaches, namely by Blouin et al. (1977), 130, and by Azaïs Braesco et al. (1997), 109. It is noteworthy that the index was relatively constant in different zones of the lobule, reinforcing the functional and structural relations between IC and hepatocytes, and emphasising the relevance of this index in hepatology.

Concerning the hepatocytes, they were counted in this and in previous studies as if all cells were "mononucleated hepatocytes" (Weibel et al., 1969). However binucleated cells are frequent in rat liver; according to an unbiased study by Jack et al. (1990), $30 \%$ of the hepatocytes are binucleated. Taking this into account, the $\mathrm{N}$ we estimated $\left(2511 \mathrm{E}^{06}\right.$ "mononucleated hepatocytes") could correspond to $1930 \mathrm{E}^{06}$ hepatocytes. Quantification of hepatocytes has been performed, namely by Weibel et al. (1969), who estimated $568 \mathrm{E}^{06}$ "mononuclated hepatocytes" per gram of liver, and by Carthew et al. (1996), who estimated $1520 \mathrm{E}^{06}$ hepatocytes per liver (including binucleated cells). These estimations differ $30 \%$ and $20 \%$, respectively, from ours. This can be accounted for by the distinct strains, ages of the animals used, and by the methodologies now in disuse employed by both authors, stressing the potential differences between the nowadays called "design-based" stereology we used, and the "assumption-based" techniques of the past.

It has been known for long that though the liver tissue looks uniform on basic histology, it is heterogeneous at the level of morphometry and histochemistry, both for hepatocytes and sinusoidal cells (Jungermann and Kietzman, 1996). To our knowledge, this is the first study to quantify, using "design-based" stereology, such lobular heterogeneity for IC and hepatocytes. The periportal predominance of IC has been suggested in 2D-analyses, both in the rat (Geerts et al., 1991, Azaïs Braesco et al., 1997) and in the pig (Wake and Sato, 1993). In theory, such predominance could be imputed to a larger reference volume of periportal zones and/or to higher numerical density $\left(\mathrm{N}_{\mathrm{V}}\right)$. In our case, the first hypothesis seems to prevail, because the $\mathrm{N}_{\mathrm{V}}$ did not differ significantly between zones (data not shown). This means that the periportal liver tissue is more abundant and thus it contains more IC (so the $\mathrm{N}$ of IC is higher), although 
there is the same IC number per unit volume. This global periportal predominance may explain the higher extracellular matrix deposition and vitamin A storing described in this zone (Geerts et al., 1994). Moreover, our results seem in "physiological" accordance with data suggesting that Kupffer cells (essential for the IC activation) also predominate in periportal zones (Jungermann and Kietzman, 1996).

Based on preliminary tests, all the sampling was designed to result in precise estimations of $\mathrm{N}$, with CE's lower than 10\% (West et al., 1996). The estimation of the CE is still a matter of debate among stereologists, and here we used two formulae based on the so-called "quadratic approximation", slightly differing in the weight given to the inter-sectional variance. Because the CE's were much similar and lower than the above cited threshold with both formulae, the conclusions were alike, and so, the sampling procedure could be considered efficient $a$ priori. In all the estimations but two, the $\mathrm{CE}$ contributed less than $50 \%$ to the total variances (i.e., the biological variance was greater than the variance due to the sampling procedure). Only in N of IC for pericentral and periportal zones, the sampling variance was superior to the biological one. However, we want to emphasise that the OCVs of these estimations were low $(<10 \%)$; so, even in those cases the sampling effort seems to be well adequate for our present purposes.

\section{REFERENCES}

Azaïs Braesco V, Hautekeete ML, Dodeman I, Geerts A (1997). Morphology of liver stellate cells and liver vitamin A content in 3,4,3',4'-tetrachlorobiphenyltreated rats. J Hepatol 27:545-53.

Blouin A, Bolender RP, Weibel ER (1977). Distribution of organelles and membranes between hepatocytes and nonhepatocytes in the rat liver parenchyma. A stereological study. J Cell Biol 72:441-55.

Bronfenmajer S, Schaffner F, Popper H (1966). Fat-storing cells (lipocytes) in human liver. Arch Pathol 82:447-53.

Buniatian G, Hamprecht B, Gebhardt R (1996). Glial fibrillary acidic protein as a marker to distinguish between the normal and myofibroblastic-like phenotypes. Biol Cell 87:65-73.

Carthew P, Maronpot RR, Foley JF, Edwards RE, Nolan BM (1996). Method for determining whether the number of hepatocytes is increased after treatment with the peroxisome proliferator Gembrozil. J Ap Toxicol 17:47-51.

Geerts A, Lazou JM, De Bleser P, Wisse E (1991). Tissue distribution, quantitation and proliferation kinetics of fat-storing cells in carbon tetrachloride-injured rat liver. Hepatology 13:1193-202.
Geerts A, De Bleser P, Hautekeete ML, Niki T, Wisse E (1994). Fat-storing (Ito) cell biology. In: Arias IM, Boyer JL, Fausto N, Jakoby WB, Schachter DA, Shafritz DA, eds. The liver: biology and pathobiology. Third edition. Ch. 42. New York: Raven Press Ltd, 819-38.

Gundersen HJG (1977). Notes on the estimation of the numerical density of arbitrary particles: the edge effect. J Microsc 111:219-23.

Gundersen HJG (1986). Stereology of arbitrary particles: a review of unbiased number and size estimators and the presentation of some new ones, in memory of William R Thompson. J Microsc 143:3-45.

Gundersen HJ, Jensen EBV, Kiêu K, Nielsen J (1999). The efficiency of systematic sampling in stereology reconsidered. J Microsc 193:199-211.

Hall WC, Rojko JL (1996). The use of immunocytochemistry for evaluating the liver. Toxicol Pathol 24:4-12.

Hatton WJ, Von Bartheld CS (1999). Analysis of cell death in the trochlear nucleus of the chick embryo: calibration of the optical disector counting method reveals systematic bias. J Comp Neurol 409:169-86.

Jack EM, Bentley P, Bieri F, Muakkassah-Kelly SF, Stäubli W, Suter J, Waechter F, Cruz-Orive LM (1990). Increase in hepatocyte and nuclear volume and decrease in the population of binucleated cells in preneoplastic foci of rat liver: a setereological study. Hepatology 11:286-97.

Jungermann K, Kietzmann T (1996). Zonation of parenchymal and nonparenchymal metabolism in liver. An Rev Nut 16:179-203.

Kawada N (1997). The hepatic perisinusoidal stellate cell. Histol Histopathol 12:1069-80.

Marcos R, Rocha E, Monteiro RAF (2001). Strategies to maximise adhesion of thick paraffin sections of the brown trout liver for stereological purposes. J Histotechnol 24:37-42.

Marcos R, Rocha E (2001). Counting GFAP-marked Ito cells using the unbiased disector principle. In: Wisse E, Knook D, Zanger R, Arthur MJP, eds. Cells of the Hepatic Sinusoid. Vol. 8. Leiden: The Kupffer Cell Foundation, 203-4.

Neubauer K, Knittel T, Aurish S, Fellmer P, Ramadori G (1996). Glial fibrillary acidic protein - a cell type specific marker for Ito cells in vivo and in vitro. $\mathrm{J}$ Hepatol 24:719-30.

Niki T, De Bleser PJ, Xu G, Van Den Berg K, Wisse E, Geerts A (1996). Comparison of glial fibrillary acidic protein and desmin staining in normal and $\mathrm{CCl}_{4}$ induced fibrotic rat livers. Hepatology 23:1538-45.

Nyengaard JR (1999). Stereologic methods and their application in kidney research. J Am Soc Nephrol 10:1100-23.

Pilegaard K, Ladefoged O (1996). Total number of astrocytes in the molecular layer of the dentate gyrus of rats at different ages. Analyt Quant Cytol Histol $18: 279-85$. 
Sztark F, Dubroca J, Latry P, Quinton A, Balabaud C, Bioulac-Sage P (1986). Perisinusoidal cells in patients with normal liver histology. A morphmetric study. J Hepatol 2:358-69.

Wake K, Sato T (1993). Intralobular heterogeneity of perisinusoidal stellate cells in porcine liver. Cell Tis Res 273:227-37.

Weibel E, Stäubli W, Gnägi HR, Hess FA (1969). Correlated morphometric and biochemical studies on the liver cell. J Cell Biol 42:68-91.
West MJ, Slomianka L, Gundersen HJG (1991). Unbiased stereological estimation of the total number of neurons in the subdivisions of the rat hippocampus using the optical fractionator. Anat Rec 231:482-97.

West MJ (1993). New stereological methods for counting neurons. Neurobiol Aging 14:275-85.

West MJ, Ostergaard K, Andreassen OA, Finsen B (1996). Estimation of the number of somatostatin neurons in the striatum: an in situ hibridization study using the optical fractionator. J Comp Neurol 370:11-22. 